lisses; sous un fort grossissement elles apparaissent très finement granuleuses. Elles sont saillantes, non rebordées, et c'est à peine si un léger sillon interrompu de quelques fossettes piligères marque la largeur du bourrelet aplati qui en limite les bords. Ecusson ventral en demi cercle, fort, sans particularités.

Pattes au nombre de 91 à 105 paires, fines, armées d'une griffe longue et grêle. Les trois à quatre derniers segments ne portent pas de pattes.

Le màle de cette espèce m'est inconnu.

Cette description est établie sur trois individus recueillis à Hendaye (Basses-Pyrénées) par M. A. Dollfus.

\title{
DESCRIPTION D'UNE PLANAIRE TERRESTRE DU TONKIN,
}

\section{par L. von GRAFF,}

Professeur à l'Université de Graz (Autriche).

Bipalium Rigaudi, nova species.

Ce Bipalium a été recueilli en 1894 à Lao-Kay (Tonkin) par le $\mathrm{D}^{\mathrm{r}}$ Rigaud; il m'a été communiqué par les $\mathrm{D}^{\mathrm{rs}} \mathrm{R}$. Blanchard et J. Richard, de Paris. C'est la première Planaire terrestre connue du Tonkin, bien que ce pays doive assurément en être très riche.

Il se distingue nettement des nombreuses autres

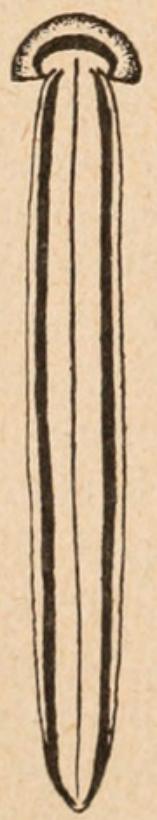
espèces de la région orientale par son dessin très caractéristique. La couleur fondamentale est jaune d'ocre vif sur le dos, jaune plus clair et plus mat sur le ventre; elle réside dans l'épithélium. Le dessin sombre est causé par un pigment noir siégeant dans le parenchyme; il consiste en une bande parallèle au bord frontal de la tête et en trois lignes longitudinales s'étendant sur le corps. La ligne médiane commence déjà à la base de la tête et est très fine ; les lignes latérales, plus larges, ne commencent que derrière la tête et convergent vers l'extrémité postérieure, mais sans se réunir.

Le bord frontal de la tête est d'un gris nuageux à sa partie dorsale; ce ton gris est causé par les yeux, qui sont accumulés en grand nombre à cet endroit. La face ventrale de la tête ne porte pas d'yeux, mais on en trouve sur la face ventrale du corps, immédiatement derrière la tête, sous 
forme de deux taches noires allongées ( taches cervicales »). En dessous des yeux frontaux se trouve, au bord ventral de la tête, la ligne incolore des fossettes sensorielles. La ligne médio-ventrale est occupée par le plan pédieux blanchâtre, un peu proémiment et occupant environ le quart de la largeur du corps.

L'unique exemplaire est long de $38^{\mathrm{mm}}$. Le corps, faiblement convexe à ses deux faces dorsale et ventrale, atteint une largeur de $4^{\mathrm{mm}} 6$; la tète est large de $6^{\mathrm{mm}}$. La bouche est à $18^{\mathrm{mm}}$, l'orifice sexuel à $22^{\mathrm{mm}}$ ว̆ de l'extrémité antérieure.

\section{NOTE SUR UNE CONTRE-EMPREINTE DE BIBIONIDAE \\ DES LIGNITES DE ROTT,}

\section{par Fernand MEUNIER.}

Les Bibionidae fossiles des différents gisements tertiaires sont relativement peu connus, parce que les paléontologistes qui les ont examinés n’avaient pas les connaissances nécessaires pour faire de minutieuses observations sur ces curieuses Mouches, dont les caractères morphologiques des antennes plaident si fortement en faveur de la doctrine évolutionniste.

Dans son mémoire sur les Diptères des lignites du Rhin, Heyden (1) décrit un Bibionidae sous le nom de Dilophus Krantzi; mais il ne dit absolument rien dans sa diagnose au sujet des signes distinctifs qui font si facilement reconnaître ces Mouches des autres genres de cette famille. Grâce à l'obligeance de M. le D ${ }^{r}$ Krantz, qui m'a communiqué un des types de Heyden, je puis signaler les erreurs commises par cet auteur.

Comme on le sait, chez les Dilophus la partie antérieure du thorax est munie d'une couronne de cils raides émergeant assez bien audessus du tégument et donnant à ces Insectes un aspect tout particulier. Ce caractère, de la plus haute importance, n'est pas mentionné par Heyden. Voici ce qu'il dit à la page 19 de son ouvrage : " Das Halschild ist sehr gross, rund, hinten am breitesten, oben gewölbt, behaar. Ein dunkler, knopfförmiger, gestielter Schwinger ist sichtbar ». Pour les ailes, il se contente seulement d'examiner et d'emprunter les caractères du genre au beau travail classique de

(1) L. von Heyden, Fossile Dipteren aus der Braunkohle von Rott im Siebengebirge, p. 19 et 20 ; Cassel, 1870. 


\section{$2 \mathrm{BHL}$ Biodiversity Heritage Library}

1894. "Description d'une Planaire terrestre du Tonkin." Bulletin de la Société zoologique de France 19, 100-101. https://doi.org/10.5962/bhl.part.1572.

View This Item Online: https://www.biodiversitylibrary.org/item/22155

DOI: https://doi.org/10.5962/bhl.part.1572

Permalink: https://www.biodiversitylibrary.org/partpdf/1572

\section{Holding Institution}

MBLWHOI Library

\section{Sponsored by}

MBLWHOI Library

\section{Copyright \& Reuse}

Copyright Status: NOT_IN_COPYRIGHT

This document was created from content at the Biodiversity Heritage Library, the world's largest open access digital library for biodiversity literature and archives. Visit BHL at https://www.biodiversitylibrary.org. 